\title{
Pre-eclampsia: pathophysiology, diagnosis, and management
}

\author{
This article was published in the following Dove Press journal: \\ Vascular Health and Risk Management \\ I8 July 201 I \\ Number of times this article has been viewed
}

\section{Jennifer Uzan' \\ Marie Carbonnel' \\ Olivier Piconne ${ }^{1,3}$ \\ Roland Asmar ${ }^{2}$ \\ Jean-Marc Ayoubi'}

'Department of Gynecology and Obstetrics, Hôpital Foch, Suresnes, France; ${ }^{2}$ Foundation Medical Research Institutes, Geneva, Switzerland; ${ }^{3}$ Department of Gynecology and Obstetrics, Hôpital Antoine Béclère, Clamart, France
Correspondence: Jean-Marc Ayoubi Service de Gynécologie et Obstétrique, Hôpital Foch, 9215I Suresnes

Cedex, France

Tel +33I 46252228

Fax +33I 46252759

Email jm.ayoubi@hopital-foch.org

\begin{abstract}
The incidence of pre-eclampsia ranges from 3\% to $7 \%$ for nulliparas and $1 \%$ to $3 \%$ for multiparas. Pre-eclampsia is a major cause of maternal mortality and morbidity, preterm birth, perinatal death, and intrauterine growth restriction. Unfortunately, the pathophysiology of this multisystem disorder, characterized by abnormal vascular response to placentation, is still unclear. Despite great polymorphism of the disease, the criteria for pre-eclampsia have not changed over the past decade (systolic blood pressure $>140 \mathrm{mmHg}$ or diastolic blood pressure $\geq 90 \mathrm{mmHg}$ and 24-hour proteinuria $\geq 0.3 \mathrm{~g}$ ). Clinical features and laboratory abnormalities define and determine the severity of pre-eclampsia. Delivery is the only curative treatment for pre-eclampsia. Multidisciplinary management, involving an obstetrician, anesthetist, and pediatrician, is carried out with consideration of the maternal risks due to continued pregnancy and the fetal risks associated with induced preterm delivery. Screening women at high risk and preventing recurrences are key issues in the management of pre-eclampsia.
\end{abstract}

Keywords: pre-eclampsia, epidemiology, pathophysiology, therapeutic management

\section{Introduction}

The criteria that define pre-eclampsia have not changed over the past decade. ${ }^{1,2}$ These are: onset at $>20$ weeks' gestational age of 24 -hour proteinuria $\geq 30 \mathrm{mg} /$ day or, if not available, a protein concentration $\geq 30 \mathrm{mg}$ ( $\geq 1+$ on dipstick) in a minimum of two random urine samples collected at least 4-6 hours but no more than 7 days apart, a systolic blood pressure $>140 \mathrm{mmHg}$ or diastolic blood pressure $\geq 90 \mathrm{mmHg}$ as measured twice, using an appropriate cuff, 4-6 hours and less than 7 days apart, and disappearance of all these abnormalities before the end of the 6 th week postpartum. Nonetheless, some presentations of pregnancy-related hypertension combined with clinical or laboratory abnormalities or intrauterine growth restriction should also be considered as potential pre-eclampsia. ${ }^{1}$

\section{Epidemiology}

Pre-eclampsia is a multisystem disorder that complicates $3 \%-8 \%$ of pregnancies in Western countries and constitutes a major source of morbidity and mortality worldwide. ${ }^{3,4}$ Overall, 10\%-15\% of maternal deaths are directly associated with preeclampsia and eclampsia. ${ }^{4}$ Some epidemiological findings support the hypothesis of a genetic and immunological etiology. The risk of pre-eclampsia is 2-fold to 5-fold higher in pregnant women with a maternal history of this disorder. Depending on ethnicity, the incidence of pre-eclampsia ranges from $3 \%$ to $7 \%$ in healthy nulliparas and $1 \%$ to $3 \%$ 
in multiparas. Moreover, nulliparity and a new partner have been shown to be important risk factors (Table 1). ${ }^{5}$

Other risk factors have been identified, including a medical history of chronic hypertension, kidney disease, diabetes, obesity, birthplace in Africa, age $\geq 35$ years, and pregnancy characteristics, such as twin or molar pregnancy, previous pre-eclampsia, or fetal congenital abnormality. ${ }^{6,7}$ High altitude has also been shown to increase the incidence of pre-eclampsia, and is attributed to greater placental hypoxia, smaller uterine artery diameter, and lower uterine artery blood flow. ${ }^{8}$

Pre-eclampsia may be life-threatening for both mother and child, increasing both fetal and maternal morbidity and mortality. ${ }^{5}$ In the mother, pre-eclampsia may cause premature cardiovascular disease, such as chronic hypertension, ischemic heart disease, and stroke, later in life, ${ }^{9}$ while children born after pre-eclamptic pregnancies and who are relatively small at birth, have an increased risk of stroke, coronary heart disease, and metabolic syndrome in adult life. ${ }^{10-12}$

The sole curative treatment being delivery, management must continuously balance the risk-benefit ratio of induced preterm delivery and maternal-fetal complications. Screening women at high risk and preventing recurrences are also key issues in the management of pre-eclampsia.

\section{Pathophysiology}

During normal pregnancy, the villous cytotrophoblast invades into the inner third of the myometrium, and spiral arteries lose their endothelium and most of their muscle fibers. These structural modifications are associated with functional alterations, such that spiral arteries become lowresistance vessels, and thus less sensitive, or even insensitive, to vasoconstrictive substances.

Pre-eclampsia has a complex pathophysiology, the primary cause being abnormal placentation. Defective invasion of the spiral arteries by cytotrophoblast cells is observed during pre-eclampsia. Recent studies have shown that cytotrophoblast invasion of the uterus is actually a unique differentiation pathway in which the fetal cells adopt certain attributes of the maternal endothelium they normally replace. In pre-eclampsia, this differentiation process goes awry. ${ }^{13}$ The abnormalities may be related to the nitric oxide pathway, which contributes substantially to the control of vascular tone. Moreover, inhibition of maternal synthesis of nitric oxide prevents embryo implantation. ${ }^{14}$ Increased uterine arterial resistance induces higher sensitivity to vasoconstriction and thus chronic placental ischemia and oxidative stress. This chronic placental ischemia causes fetal complications, including intrauterine growth retardation and intrauterine death. In parallel, oxidative stress induces release into the maternal circulation of substances such as free radicals, oxidized lipids, cytokines, and serum soluble vascular endothelial growth factor 1 . These abnormalities are responsible for endothelial dysfunction ${ }^{15}$ with vascular hyperpermeability, thrombophilia, and hypertension, so as to compensate for the decreased flow in the uterine arteries due to peripheral vasoconstriction.

Endothelial dysfunction is responsible for the clinical signs observed in the mother, ie, impairment of the hepatic endothelium contributing to onset of the HELLP (Hemolysis, Elevated Liver enzymes and Low Platelet count) syndrome, impairment of the cerebral endothelium inducing refractory neurological disorders, or even eclampsia. Depletion of vascular endothelial growth factor in the podocytes makes the endotheliosis more able to block the slit diaphragms in the basement membrane, adding to decreased glomerular filtration and causing proteinuria. Finally, endothelial dysfunction promotes microangiopathic hemolytic anemia, and vascular hyperpermeability associated with low serum albumin causes edema, particularly in the lower limbs or lungs.

The crucial issue to understand is that the prime mover of pre-eclampsia is abnormal placentation. Two common theories appear to be interlinked, ie, a genetic theory ${ }^{1,16}$ and an immunological theory. ${ }^{17,18}$ Several susceptibility genes may exist for pre-eclampsia. ${ }^{16,19}$ These genes probably interact in the hemostatic and cardiovascular systems, as well as in the inflammatory response. Some have been identified, and in candidate gene studies they have provided evidence of linkage to several genes, including angiotensinogen on 1-q42-43 and eNOS on 7q36; other main important loci are 2 p12, 2 p25, 9p13, and 10q22.1.16

Pre-eclampsia can be perceived as an impairment of the maternal immune system that prevents it from recognizing the fetoplacental unit. Excessive production of immune cells causes secretion of tumor necrosis factor alpha which induces apoptosis of the extravillous cytotrophoblast. ${ }^{17}$ The human leukocyte antigen (HLA) system also appears to play a role in the defective invasion of the spiral arteries, in that women with pre-eclampsia show reduced levels of HLA-G and HLA-E. ${ }^{18}$ During normal pregnancies, the interaction between these cells and the trophoblast is due to secretion of vascular endothelial growth factor and placental growth factor by natural killer cells. High levels of soluble fms-like tyrosine kinase 1 (sFlt-1), an antagonist of vascular endothelial growth factor and placental growth factor, have been found in women with pre-eclampsia. ${ }^{17,18}$ 
Accordingly, assays of sFlt-1, placental growth factor, endoglin, and vascular endothelial growth factor, all of which increase 4-8 weeks before onset of the disease, may be useful predictors of pre-eclampsia. Recent data show the protective role of heme oxygenase 1 and its metabolite, carbon monoxide, in pregnancy, and identify this as a potential target in the treatment of pre-eclampsia. ${ }^{20}$

\section{Clinical presentation and workup findings}

Clinical and laboratory tests are intended to define and determine the severity of pre-eclampsia. Headaches, tinnitus, phosphene signals, visual disorders, brisk tendon reflexes, and vigilance disorders are related to cerebral edema; oliguria to acute renal failure; uterine contraction, vaginal bleeding to placental abruption; vomiting to HELLP syndrome; bandlike epigastric pain to subcapsular hepatic hematoma; and dyspnea to cardiac failure. Eclampsia, the major neurological complication of pre-eclampsia, is defined as a convulsive episode or any other sign of altered consciousness arising in a setting of pre-eclampsia, and which cannot be attributed to a pre-existing neurological condition. Clinical examination should include resting blood pressure measurement using an appropriate cuff, and screening for weight gain, edema (including signs of acute pulmonary edema and cerebral edema), cardiomyopathy, and acute renal failure. The fetus should be assessed by electrocardiotocography. Laboratory tests include: a complete blood count with platelets, haptoglobin, and lactate dehydrogenase; a blood smear to test for schistocytes; bilirubin, aspartate transaminase, and alanine transaminase in order to identify potential HELPP syndrome; electrolyte, urea, and creatinine assessment to check for acute renal failure or uremia; 24-hour proteinuria; prothrombin, activated thrombin time, and fibrinogen (microangiopathic hemolytic anemia); blood group; and irregular antibody screening. Other examinations include fetal ultrasound with Doppler velocimetry of the umbilical, cerebral, and uterine arteries, estimation of fetal weight, assessment of fetal well-being by Manning score, and examination of the placenta. ${ }^{21}$

Although the definition of severe pre-eclampsia varies, ${ }^{1,21,22}$ several components of this definition are usually accepted: maternal systolic blood pressure $\geq 160 \mathrm{mmHg}$ or diastolic blood pressure $\geq 110 \mathrm{mmHg}$; maternal neurological disorders such as persistent headaches, phosphene signals, tinnitus, and brisk, diffuse, polykinetic tendon reflexes, eclampsia, acute pulmonary edema, proteinuria $\geq 5 \mathrm{~g} /$ day, oliguria $<500 \mathrm{cc} /$ day, creatinine $>120 \mu \mathrm{mol} / \mathrm{L}$, HELLP syndrome, thrombocytopenia $<100,000 / \mathrm{mm}^{3}$, and fetal criteria, especially intrauterine growth retardation, oligohydramnios, or fetal death in utero. Mild pre-eclampsia is defined as diastolic blood pressure $\geq 90 \mathrm{mmHg}$ measured on two occasions at least 6 hours apart, combined with proteinuria (two or more occurrences of protein on dipstick, $>300 \mathrm{mg}$ total protein in a 24 -hour urine collection, or a protein creatinine ratio $>30 \mathrm{mg} / \mathrm{mmol}$ ). ${ }^{1}$

\section{Immediate emergency management}

Delivery is the only curative treatment for pre-eclampsia. ${ }^{1}$ Management is multidisciplinary, involving an obstetrician, an anesthetist, and a pediatrician. In some cases consultation of maternal fetal medicine and hypertension or nephrology subspecialists may be required. Management decisions must balance the maternal risks of continued pregnancy against the fetal risks associated with induced preterm delivery. ${ }^{2}$ The criteria for delivery are based on two often interrelated factors, ie, gestational age at diagnosis (estimated fetal weight) and severity of pre-eclampsia.

Severe pre-eclampsia requires treatment with a dual aim, ie, preventing the harmful effects of elevated maternal blood pressure and preventing eclampsia. Management of severe pre-eclampsia begins with transfer of the mother in a fully equipped ambulance or helicopter to a maternity ward providing an appropriate level of care for both mother and child. ${ }^{2}$ At admission and daily thereafter, clinical, cardiotocographic, laboratory, and ultrasound testing are required to detect the severity of pre-eclampsia and tailor management accordingly. ${ }^{22}$

Regardless of the severity of pre-eclampsia, there is no advantage in continuing the pregnancy when pre-eclampsia is discovered after $36-37$ weeks. ${ }^{23-25}$ Nor is expectant management justified for severe pre-eclampsia before 24 weeks, in view of the high risk of maternal complications and the poor neonatal prognosis. ${ }^{26-28}$ The obstetric team must then discuss with the parents the possibility of a medical interruption of pregnancy. Prolongation of pregnancy in the event of mild pre-eclampsia can be discussed and reevaluated on a regular basis. At 34-37 weeks, management depends on the severity of the pre-eclampsia. Expectant management is possible for mild pre-eclampsia to limit the risk of induced preterm delivery, but for severe pre-eclampsia, delivery remains the rule due to the increased risk of maternal and fetal complications. ${ }^{2,22}$

Similarly, at 24-34 weeks, management depends on the severity of pre-eclampsia. The presence of one or 
more of the following signs indicates the need for immediate delivery: uncontrolled severe hypertension (not responsive to dual therapy), eclampsia, acute pulmonary edema, abruptio placentae, subcapsular hepatic hematoma, or thrombocytopenia $<50,000 / \mathrm{mm}^{3}$. Delivery after corticosteroid therapy for pulmonary maturation is necessary if any of the following criteria is present: persistent epigastric pain, signs of imminent eclampsia (headaches or persistent visual disorders), de novo creatinine $>120 \mu \mathrm{mol} / \mathrm{L}$, oliguria below $20 \mathrm{~mL} /$ hour, progressive HELLP syndrome, prolonged or severe variable decelerations with short-term variability less than 3 milliseconds. When emergency delivery is not required, labor can be induced by cervical ripening. ${ }^{22}$

Antihypertensive treatment is useful only in severe preeclampsia because the sole proven benefit of such management is to diminish the risk of maternal complications (cerebral hemorrhage, eclampsia, or acute pulmonary edema). ${ }^{29}$ There is no international consensus concerning antihypertensive treatment in pre-eclampsia. The four drugs authorized for the treatment of hypertension in severe pre-eclampsia in France are nicardipine, labetalol, clonidine, and dihydralazine. ${ }^{29}$ There is no ideal target blood pressure value, and too aggressive a reduction in blood pressure is harmful to the fetus. ${ }^{30}$ Therapy with a single agent is advised as first-line treatment, followed by combination treatment when appropriate. The algorithm for antihypertensive treatment proposed by French experts ${ }^{22}$ is shown in Figure 1.

Pulmonary maturation using corticosteroids must be considered, taking gestational age into account. Betamethasone remains the gold standard at a dosage of two injections of $12 \mathrm{mg} 24$ hours apart; this treatment reduces the risk of hyaline membrane disease, intraventricular hemorrhage, and neonatal mortality. ${ }^{31}$

Magnesium sulfate (MgSO4) may be part of the therapeutic armamentarium for severe pre-eclampsia. It is indicated in the treatment of eclamptic convulsions as well as for secondary prevention of eclampsia, thus replacing treatment by diazepam, phenytoin, or the combination of chlorpromazine, promethazine, and pethidine. ${ }^{32}$ The efficacy of $\mathrm{MgSO} 4$ in the reduction of maternal and neonatal complications of eclampsia is well established. It is administered intravenously, first at a loading dose of $4 \mathrm{~g}$ over 15-20 minutes, which can be repeated at a half dose $(2 \mathrm{~g})$ if convulsion recurs, and then at a maintenance dose of $1 \mathrm{~g}$ /hour for 24 hours. ${ }^{22,32} \mathrm{MgSO} 4$ treatment must be monitored in the intensive care unit because organ failure may occur. This monitoring is based on repeated checking for a Glasgow score of 15 , tendon reflexes, respiratory frequency $>12$ per minute, and diuresis $>30 \mathrm{~mL} /$ hour. Any manifestation of overdose requires stopping the infusion, considering injection of calcium gluconate, and measuring blood magnesium levels. ${ }^{22}$

Eclampsia is generally considered an indication for emergency cesarean section. Nonetheless, a decision to delay a cesarean, albeit rare, may be based on fetal status and justified if the mother's condition is stable and reassuring after treatment. ${ }^{33}$

\section{Management following delivery}

Although delivery is the only effective treatment for pre-eclampsia, and despite the fact that clinical symptoms and laboratory abnormalities usually regress in the hours afterwards, the risk of complications persists for some time following delivery. ${ }^{6}$ Pre-eclampsia is associated with longterm morbidity and mortality. Approximately $20 \%$ of women with pre-eclampsia develop hypertension or microalbuminuria during long-term follow-up, and the risk of subsequent cardiovascular and cerebrovascular disease is doubled in women with pre-eclampsia and gestational hypertension compared with age-matched controls. ${ }^{34} \mathrm{~A}$ recent prospective epidemiological study with a median follow-up duration of 30 years provides evidence that pre-eclampsia is a marker of increased mortality from cardiovascular disease. ${ }^{35}$

Hemodynamic, neurological, and laboratory monitoring is necessary following delivery for patients with severe preeclampsia. ${ }^{36}$ Hemodynamic monitoring includes frequent blood pressure measurements to enable adjustment of antihypertensive treatment and frequent monitoring of diuresis and weight according to intake (oliguria should prompt progressive fluid resuscitation and sometimes diuretic use). Neurological monitoring consists of checking for signs of imminent eclampsia, including headaches, phosphene signals, tinnitus, and brisk tendon reflexes. Clinical monitoring must be done several times daily during the week after delivery, a period considered at high risk for complications. If necessary, monitoring can be performed in an intensive care unit.

Laboratory monitoring should be done several times daily in the first 72 hours after delivery and thereafter adapted according to progress of the indices. It must include a complete blood count, liver function tests, and measurement of lactate dehydrogenase. Discharge from hospital cannot be considered until all clinical and laboratory indices have returned to normal, and regular monitoring by the patient's general practitioner as necessary if treatment for hypertension is to be continued after discharge. 


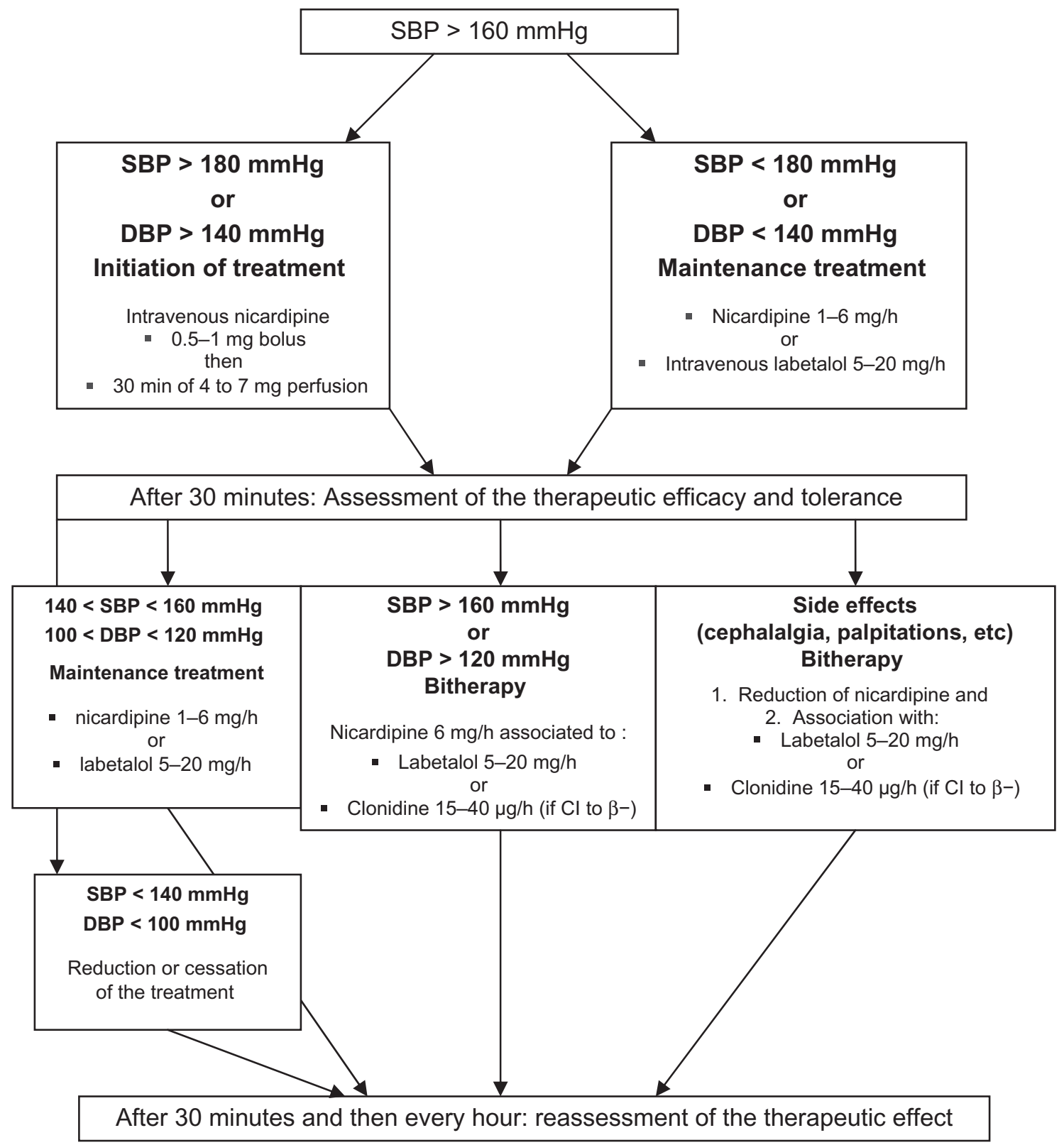

Figure I Algorithm for antihypertensive treatment of pre-eclampsia. ${ }^{22}$

Note: $\mathrm{MBP}=[$ systolic $\mathrm{BP}+2 \times$ diastolic BP]/3.

Abbreviations: MBP, mean blood pressure; $\mathrm{Cl}$, contraindication; SBP, systolic blood pressure; DBP, diastolic blood pressure.

The risk of recurrence of pre-eclampsia during a subsequent pregnancy has to be considered. This risk is estimated to be less than $10 \%$ for all cases of pre-eclampsia, ${ }^{37}$ but is greater when pre-eclampsia is discovered before 28 weeks. The relative risk is 15 if pre-eclampsia occurs at $20-33$ weeks, 10 at 33-36 weeks, and 8 after 37 weeks. ${ }^{37}$

Three months after delivery, screening for underlying renal or hypertensive disease may be requested by the patient's primary physician. Such screening is intended to check for normalization of blood pressure values and disappearance of proteinuria, and if abnormalities persist, a referral should be made to a nephrologist or a hypertension expert to determine the cause. This examination is important because pre-eclampsia may unmask previously undiagnosed systemic or kidney disease or thrombophilia. It should include a specific set of questions, blood pressure measurement, a clinical examination looking for signs of autoimmune conditions, and a urinary dipstick test. Testing for antiphospholipid antibodies is recommended after severe pre-eclampsia. The search for hereditary thrombophilia by assays for protein $\mathrm{C}$ and $\mathrm{S}$, antithrombin III, and a test for resistance to activated protein $\mathrm{C}$ is recommended in the case 
Table I Major risk factors for pre-eclampsia ${ }^{49}$

\begin{tabular}{ll}
\hline Risk factor & OR or RR (95\% CI) \\
\hline $\begin{array}{l}\text { Antiphospholipid antibody } \\
\text { syndrome }\end{array}$ & $9.7(4.3-21.7)$ \\
Renal disease & $7.8(2.2-28.2)$ \\
Prior pre-eclampsia & $7.2(5.8-8.8)$ \\
Systemic lupus erythematosus & $5.7(2.0-16.2)$ \\
Nulliparity & $5.4(2.8-10.3)$ \\
Chronic hypertension & $3.8(3.4-4.3)$ \\
Diabetes mellitus & $3.6(2.5-5.0)$ \\
High altitude & $3.6(1.1-11.9)$ \\
Multiple gestations & $3.5(3.0-4.2)$ \\
Strong family history of CV disease & $3.2(1.4-7.7)$ \\
(heart disease or stroke & \\
in $\geq 2$ first-degree relatives) & \\
Obesity & $2.5(1.7-3.7)$ \\
Family history of pre-eclampsia & $2.3-2.6(1.8-3.6)$ \\
in first-degree relative & \\
Advanced maternal age & $1.68(1.23-2.29)$ for nulliparas \\
(>40 years) & $1.96(1.34-2.87)$ for multíparas \\
\hline
\end{tabular}

Abbreviations: $\mathrm{Cl}$, confidence interval; $\mathrm{OR}$, odds ratio; $\mathrm{RR}$, relative risk; $\mathrm{CV}$, cardiovascular.

of a personal or family history of venous thromboembolic disease, early pre-eclampsia, or pre-eclampsia with any intrauterine growth retardation, abruptio placentae, or in utero death. ${ }^{22,38}$ Percutaneous needle biopsy of the kidney should be performed only if kidney failure persists at three months postpartum or if signs of a systemic underlying condition or proteinuria persist at 6 months. ${ }^{23}$

Patients who have had severe pre-eclampsia may share predispositions with nonpregnant patients who have cardiovascular risk factors. ${ }^{39}$ Accordingly, long-term monitoring of cardiovascular, renal, and metabolic risk factors is recommended after severe pre-eclampsia. ${ }^{22}$

\section{Prevention}

Primary prevention of pre-eclampsia is based on the detection of modifiable risk factors. The literature is plentiful regarding the risk factors for pre-eclampsia, but should be interpreted with caution. ${ }^{4-8}$ Women at high risk are those with a personal history of severe pre-eclampsia, while those at low risk are defined as those who have never had pre-eclampsia but have at least one risk factor. ${ }^{2}$ There are numerous risk factors, ${ }^{4-8}$ including genetic risk factors, family history of pre-eclampsia, immunologic factors, nulliparity, a new partner, and demographic factors such as a maternal age $>35$ years, the woman's own gestational age and birth weight (with elevated risks for women born before 34 weeks or weighing less than $2500 \mathrm{~g}$ at birth), factors related to the pregnancy, such as multiple pregnancy, congenital or chromosomal anomalies, a hydatidiform mole, or urinary infection, risk factors associated with maternal disease, including chronic hypertension, kidney disease, obesity, insulin resistance, and diabetes, as well as thrombophilia, and environmental factors such as living at a high altitude and stress. Although the search for these risk factors is important, they may not effectively predict this pre-eclampsia by themselves.

However, accurate prediction of pre-eclampsia would enable early and optimal management of women at high risk. Several predictive tests are being assessed currently. These include clinical tests, such as blood pressure measurement during the second trimester or 24-hour ambulatory blood pressure monitoring, but these lack sensitivity and specificity. ${ }^{40}$ Laboratory tests for oxidative response have been assessed, including assays for uric acid, urinary kallikrein, and fibronectin, but no evidence of their relevance has so far been found. ${ }^{40}$ Among the markers used to screen for trisomy 21 during the second trimester (beta human chorionic gonadotropin, alpha fetoprotein, and unconjugated estriol), elevated alpha fetoprotein is associated with a higher risk of pre-eclampsia (unless there are neural tube abnormalities, as when beta human chorionic gonadotropin is elevated). Frequent monitoring of women with elevated levels could be useful, but these tests may not be carried out for screening purposes due to their low negative predictive value. ${ }^{40}$ Serum markers for trisomy 21 in the first trimester (pregnancyassociated plasma protein A, inhibin A, corticotropinreleasing hormone, and activin) have been tested, but their likelihood ratios seem to be insufficient.

Imaging tests have been evaluated, including uterine artery Doppler ultrasound. ${ }^{41,42}$ Uterine artery Doppler ultrasound is not advised during the first or second trimester in low-risk populations due to the excessive variability of likelihood ratios in this population, which allows for the prediction of only one-third of pre-eclampsia cases. ${ }^{43}$ In a high-risk population, the definition of which is often imprecise, uterine artery Doppler can be performed during the second trimester morphologic ultrasound examination and checked 1 month later in case of abnormal results (resistance index $>0.58$ or $90-95$ th percentile, unilateral or bilateral notch). The combination of a uterine artery Doppler examination during the first trimester and a three-dimensional ultrasound assessing placental volume may predict the risk of pre-eclampsia as early as the first trimester. ${ }^{44}$

In clinical practice, because no single marker effectively predicts the risk of pre-eclampsia, the current trend is to test a combination of markers. The most commonly used combination of markers assesses sFlt-1, placental growth 
factor, endoglin, and vascular endothelial growth factor during the first or second trimester. Increased vascular endothelial growth factor and endoglin levels, combined with increased sFlt-1 and decreased placental growth factor during the first trimester, is associated with a significantly increased risk of pre-eclampsia. ${ }^{20}$

Improved prediction of pre-eclampsia has been noticed when serum markers are combined with Doppler indices. In a recent nested case-control study, second trimester maternal serum cystatin C, C-reactive protein, and uterine artery mean resistance index were observed to be independent predictors of pre-eclampsia. ${ }^{45}$

Secondary prevention is based on antiplatelet aspirin therapy, which reduces the risk of pre-eclampsia by $10 \%$ in women who have at least one risk factor. ${ }^{46}$ No study currently allows determination of the exact dosage or the best time for initiation of aspirin. However, aspirin should be initiated as early as possible, ie, before 12-14 weeks, which corresponds to the beginning of the first phase of trophoblast invasion. The efficacy of aspirin has been shown only in women with previous pre-eclampsia associated with intrauterine growth retardation and without thrombophilia. Low molecular weight heparin is indicated only in cases of complicated thrombophilia (history of thromboembolic complications or of pre-eclampsia). ${ }^{47}$ Calcium supplementation at a dosage of $1.5 \mathrm{~g} /$ day, beginning at 15 weeks and continued throughout the pregnancy, is recommended for prevention of pre-eclampsia in women with a daily calcium intake $<600 \mathrm{mg} /$ day. ${ }^{48}$ The statins, which stimulate HO-1 expression and inhibit sFlt-1 release, could have the potential to ameliorate early-onset pre-eclampsia. ${ }^{20}$ Other treatments, such as antioxidant treatment by vitamins $\mathrm{C}$ and $\mathrm{E}$, oligoelements, and nitric oxide have no proven efficacy. ${ }^{6}$

\section{Conclusion}

Pre-eclampsia is a rare pregnancy-related disease with an unpredictable course that can have serious consequences for both the mother and the fetus. The treatment is simple, ie, delivery. Nonetheless, induced preterm delivery requires careful weighing of both maternal and fetal riskbenefit. Accordingly, identifying delivery criteria in case of pre-eclampsia is crucial to optimal management. Current research focuses on the prediction of onset of pre-eclampsia or even severe pre-eclampsia so as to allow early management and improve the morbidity and mortality associated with this disease. Specific tools for secondary prevention must also be developed for recurrent pre-eclampsia.

\section{Disclosure}

The authors report no conflicts of interest in this work.

\section{References}

1. Sibai B, Dekker G, Kupferminc M. Pre-eclampsia. Lancet. 2005;365: 785-799.

2. Pottecher T, Luton D. Prise en Charge Multidisciplinaire de la Prééclampsie. Issy Les Moulineaux, France: Elsevier Masson SAS; 2009. French.

3. Carty DM, Delles C, Dominiczak AF. Preeclampsia and future maternal health. J Hypertens. 2010;28:1349-1355.

4. Duley L. The global impact of pre-eclampsia and eclampsia. Semin Perinatol. 2009;33:130-137.

5. Zhang J, Zeisler J, Hatch MC, Berkowitz G. Epidemiology of pregnancy-induced hypertension. Epidemiol Rev. 1997;19:218-232.

6. Barton JR, Sibai BM. Prediction and prevention of preeclampsia. Obstet Gynecol. 2008;112(2 Pt 1):359-372.

7. Rijhsinghani A, Yankowitz J, Strauss AR, et al. Risk of preeclampsia in second-trimester triploid pregnancies. Obstet Gynecol. 1997;90: 884-888.

8. Julian CG. High altitude during pregnancy. Clin Chest Med. 2011;32: $21-31$.

9. Meads CA, Cnossen JS, Meher S, et al. Methods of prediction and prevention of preeclampsia: systematic reviews of accuracy and effectiveness literature with economic modelling. Health Technol Assess. 2008;12:1-270.

10. Osmond C, Kajantie E, Forsén TJ, Eriksson JG, Barker DJ. Infant growth and stroke in adult life: the Helsinki Birth Cohort Study. Stroke. 2007;38:264-270.

11. Eriksson JG, Forsén T, Tuomilheto J, Osmond C, Barker DJ. Early growth and coronary heart disease in later life: longitudinal study. $B M J$. 2001;322:949-953.

12. Barker DJ, Martyn CN, Osmond C, Hales CN, Fall CH. Growth in utero and serum cholesterol concentrations in adult life. BMJ. 1993; 307:1524-1527.

13. Fisher SJ, McMaster M, Roberts M. The placenta in normal pregnancy and preeclampsia. In: Chesley's Hypertensive Disorders in Pregnancy. Amsterdam, the Netherlands: Academic Press, Elsevier; 2009.

14. Duran-Reyes G, Gomes-Melendez MR, Morali De La Brena G, MrecadoPichardo E, Medina-Navarro R, Hicks-Gomez JJ. Nitric oxide synthesis inhibition suppresses implantation and decreases CGMP concentration and protein peroxidation. Life Sci. 1999;65:2259-2268.

15. Roberts JM. Endothelial dysfunction in preeclampsia. Semin Reprod Endocrinol. 1998;16:5-15.

16. Mutze S, Rudnik-Schoneborn S, Zerres K, Rath W. Genes and the preeclampsia syndrome. J Perinat Med. 2008;36:38-58.

17. Genbacev O, Difederico E, McMaster M, Fisher SJ. Invasive cytotrophoblast apoptosis in pre-eclampsia. Hum Reprod. 1999;14:59-66.

18. Colbern GT, Chiang MH, Main EK. Expression of the nonclassic histocompatibility antigen HLA-G by preeclamptic placenta. Am J Obstet Gynecol. 1994;170:1244-1250.

19. Nilsson E, Salonen Ros H, Cnattingius S, Lichtenstein P. The importance of genetic and environmental effects for pre-eclampsia and gestational hypertension: a family study. BJOG. 2004;111:200-206.

20. Ahmed A. New insights into the etiology of preeclampsia: identification of key elusive factors for the vascular complications. Thromb Res. 2011;127(Suppl 3):S72-S75.

21. [No authors listed]. Report of the National High Blood Pressure Education Program Working Group on high blood pressure in pregnancy. Am J Obstet Gynecol. 2000;133:S1-S22.

22. Multidisciplinary management of severe pre-eclampsia (PE). Experts' guidelines 2008. Société française d'anesthésie et de réanimation. Collège national des gynécologues et obstétriciens français. Société française de médecine périnatale. Société française de néonatalogie. Ann Fr Anesth Reanim. 2009;28:275-281. 
23. Haddad B, Kayem G, Deis S, Sibai BM. Are perinatal and maternal outcomes different during expectant management of severe preeclampsia in the presence of intrauterine growth restriction? Am J Obstet Gynecol. 2007;196:237. e1-e5.

24. Koopmans CM, Bijlenga D, Groen H, et al. Induction of labour versus expectant monitoring for gestational hypertension or mild pre-eclampsia after 36 weeks' gestation (HYPITAT): a multicentre, open-label randomised controlled trial. Lancet. 2009;374:979-988.

25. Haddad B, Sibai BM. Expectant management in pregnancies with severe pre eclampsia. Semin Perinatol. 2009;33:143-151.

26. Haddad B, Deis S, Goffinet F, Paniel BJ, Cabrol D, Sibai BM. Maternal and perinatal outcomes during expectant management of 239 severe preeclamptic women between 24 and 33 weeks' gestation. Am J Obstet Gynecol. 2004;190:1590-1595.

27. Jenkins SM, Head BB, Hauth JC. Severe preeclampsia at $<25$ weeks of gestation: maternal and neonatal outcomes. Am J Obstet Gynecol. 2002;186:790-795.

28. Budden A, Wilkinson L, Buksh MJ, McCowan L. Pregnancy outcome in women presenting with pre-eclampsia at less than 25 weeks gestation. Aust N Z J Obstet Gynaecol. 2006;46:407-412.

29. Duley L, Henderson-Smart J, Meher S. Drugs for treatment of very high blood pressure during pregnacy. Cochrane Database Syst Rev. 2006;(3):CD001449.

30. Olsen KS, Beier-Holgersen R. Fetal death following labetalol administration in pre-eclampsia. Acta Obstet Gynecol Scand. 1992;7:145-147.

31. Amorin MMR, Santos LC, Faundes A. Corticosteroid therapy for prevention of respiratory distress syndrome in severe pre eclampsia. Am J Obstet Gynecol. 1999;180:1283-1288.

32. Pryde PG, Mittendorf R. Contemporary usage of obstetric magnesium sulfate: indication, contraindication, and relevance of dose. Obstet Gynecol. 2009;114:669-673.

33. Sibai BM. Diagnosis, prevention and management of eclampsia. Am Coll Obstet Gynecol. 2005;105:402-410.

34. Smith GC, Pell JP, Walsh D. Pregnancy complications and maternal risk of ischemic heart disease: a retrospective cohort study of 129,290 births. Lancet. 2001;357:2002-2006.

35. Funai EF, Friedlander Y, Paltiel O, et al. Long-term mortality after preeclampsia. Epidemiology. 2005;16:206-215.

36. Tan LK, de Swiet M. The management of postpartum hypertension. BJOG. 2002;109:733-736.

37. Mostello D, Catlin TK, Roman L, Holcomb WL Jr, Leet T. Preeclampsia in the parous woman: who is at risk? Am JObstet Gynecol. 2002;187:425-429.
38. Royal College of Obstetricians and Gynaecologists. Pre-eclampsia study group consensus statement. Available from: http://www.rcog. org.uk/womens-health/clinical-guidance/pre-eclampsia-study-groupconsensus-statement. Accessed June 8, 2011.

39. Irgens HU, Reisaeter L, Irgens LM, Lie RT. Long term mortality of mothers and fathers after pre eclampsia: population based cohort study. BMJ. 2001;323:1213-1217.

40. Conde-Agudelo A, Villar J, Lindheimer M. World Health Organization systematic review of screening tests for preeclampsia. Obstet Gynecol. 2004;104:1367-1391.

41. Gomez O, Martinez JM, Figueras F, et al. Uterine artery Doppler at 11-14 weeks of gestation to screen for hypertensive disorders and associated complications in an unselected population. Ultrasound Obstet Gynecol. 2005;26:490-494.

42. Rizzo G, Capponi A, Cavicchioni O, Vendola M, Arduini D. First trimester uterine Doppler and three-dimensionnal ultrasound placental volume calculation in predicting pre-eclampsia. Eur J Obstet Gynecol Reprod Biol. 2008;138:147-151.

43. Maynard SE, Min JY, Merchan J, et al. Excess placental soluble fms-like tyrosine kinase 1 (sFlt1) may contribute to endothelial dysfunction, hypertension, and proteinuria in preeclampsia. $J$ Clin Invest. 2003;111:649-658.

44. Espinoza J, Romero R, Nien JK, et al. Identification of patients at risk for early onset and/or severe preeclampsia with the use of uterine artery Doppler velocimetry and placental growth factor. Am J Obstet Gynecol. 2007;196:326. e1-e13.

45. Thilaganathan, Wormald B, Zanardini C, Sheldon J, Ralph E, Papageorghiou AT. Early-pregnancy multiple serum markers and second-trimester uterine artery Doppler in predicting preeclampsia. Obstet Gynecol. 2010;115:1233-1238.

46. Askie LM, Duley L, Henderson-Smart DJ, Stewart LA. Antiplatelet agents for prevention of pre-eclampsia: a meta-analysis of individual patient data. Lancet. 2007;369:1791-1798.

47. Sergio F, Maria Clara D, Gabriella F, et al. Prophylaxis of recurrent preeclampsia: low-molecular-weight heparin plus low-dose aspirin versus low-dose aspirin alone. Hypertens Pregnancy. 2006;25: 115-127.

48. Villar J, Abdel-Aleem H, Merialdi M, et al. World Health Organization randomized trial of calcium supplementation among low calcium intake pregnant women. Am J Obstet Gynecol. 2006;194:639-649.

49. Maynard SE, Karumanchi SA, Thadhani R. Hypertension and kidney disease in pregnancy. In: Brenner BM, editor. Brenner and Rector's The Kidney. 8th ed. Philadelphia, PA: WB Saunders; 2007.
Vascular Health and Risk Management

\section{Publish your work in this journal}

Vascular Health and Risk Management is an international, peerreviewed journal of therapeutics and risk management, focusing on concise rapid reporting of clinical studies on the processes involved in the maintenance of vascular health; the monitoring, prevention and treatment of vascular disease and its sequelae; and the involvement of

\section{Dovepress}

metabolic disorders, particularly diabetes. This journal is indexed on PubMed Central and MedLine. The manuscript management system is completely online and includes a very quick and fair peer-review system, which is all easy to use. Visit http://www.dovepress.com/ testimonials.php to read real quotes from published authors. 